\title{
CICLO DE VIDA DE SARCONESIA CHLOROGASTER (WIEDEMANN) (DIPTERA, CALLIPHORIDAE, TOXOTARSINAE), CRIADA SOB CONDIÇÕES DE LABORATÓRIO EM DIETA ARTIFICIAL ${ }^{1}$
}

\author{
Sionei Ricardo Bonatto ${ }^{2}$
}

\begin{abstract}
Life cycle of SARConesi chlorogaster (Wiedemann) (Diptera, CALliphoridaE, TOXOTARSINAE), REARED UNDER LABORATORY CONDITIONS ON ARTIFICIAL DIET. Bionomic characteristics of Sarconesia chlorogaster (Wiedemann, 1830) were obtained, rearing it with an artificial diet and a controlled temperature chamber set at $27 \pm 1^{\circ} \mathrm{C}, 70 \pm 10 \% \mathrm{RH}$ and 12 hours photophase. The duration of the whole evolutive cycle of $S$. cholorogaster was about 19.61 days. The incubation period was the shortest ( 14.30 hours), the pupal one (pre-pupal and pupal together) was the longest ( 9.57 days), followed by the larval period that had about 9.44 days. A life table for immature stages was done in order to obtain a survival curve. The average of the adults longevity was about 25.28 days. There is no statistical difference between the duration of male and female longevity. The duration of the periods of pre-posture and posture were almost the same ( 8.41 and 10.96 days respectively), but the period of pos-posture was the shortest ( 5.15 days). The life tables for adults, males and females were also done and the survival curves were obtained. The results were similar for both sexes. Through the life table of fertility the number of generations of $S$. chlorogaster was estimated to be 9.81 generations/year. The females had a high fertility under the laboratory conditions used.
\end{abstract}

KEY WORDS. Diptera, Calliphoridae, Sarconesia chlorogaster, bionomics, artificial diet

Considerado o grupo mais generalizado dos Oestroidea (RoBACK 1951), a família Calliphoridae compreende espécies tipicamente necrófagas e saprófagas, cujas larvas são os principais decompositores iniciais de matéria orgânica animal ou vegetal, ou são causadoras de miíases, acidentais ou obrigatórias, no homem ou animais (ZUMPT 1965; GREENBERG 1971; BAUMGARTNER \& GREENBERG 1985).

Do ponto de vista médico-sanitário há uma crescente preocupação epidemiológica com este grupo de insetos dada a sua grande capacidade de dispersão, elevada densidade populacional e diversificado hábito alimentar - variando desde fezes e excrementos, lixo residencial e hospitalar, até alimentos frescos - aliados ao alto grau de sinantropia e endofilia, tornando-os potenciais transmissores de agentes enteropatogênicos ao homem e animais domésticos (GREENBERG 1971; MARILUIS 1982; GUIMARÃES et al. 1983; FurLANETTO et al. 1984; MARILUIS et al. 1989).

1) Contribuição número 942 do Departamento de Zoologia, Universidade Federal do Paraná.

2) Departamento de Zoologia, Universidade Federal do Paraná. Caixa Postal 19020, 81531-990 Curitiba, Paraná, Brasil. Bolsista do CNPq.

E-mail: srbona@bio.ufpr.br 
Enquanto Calliphoridae possui vasta distribuição geográfica, Sarconesia chlorogaster (Wiedemann, 1830) é encontrada exclusivamente na América do Sul, entre $10^{\circ}$ e $40^{\circ} \mathrm{S}$, sendo a única espécie de Toxotarsinae que ocorre no Brasil, onde sua distribuição está limitada aos estados da Região Sul do país (MELLo 1972; DEAR 1979; LOPES \& ALBUQUERQUE 1982; QUEIROZ et al. 1985).

O presente estudo tem como justificativa principal, a carência de estudios anteriores sobre aspectos bionômicos relacionando-os à sistemática, principalmente das formas imaturas, de S. chlorogaster.

\section{MATERIAL E MÉTODOS}

\section{Coleta de ADULtos}

Os espécimens adultos foram coletados na região de Curitiba, próximo ao Departamento de Zoologia de Universidade Federal do Paraná, com armadilhas para moscas descritas por FERREIRA (1978). Como isca foi utilizado peixe com 24 horas de decomposicão, pois Sarconesia chlorogaster é um dos Calliphoridae mais freqüentes neste tipo de isca (FERREIRA 1978; BAUMGARTNER \& GREENBERG 1985).

\section{OBTENÇÃO E MANUTENÇÃO DOS ESTOQUES}

Os adultos coletados (machos e fềmeas) foram acondicionados um a um em tubos de ensaio com $10,0 \mathrm{~cm}$ de altura por $1,5 \mathrm{~cm}$ de diâmetro, com a extremidade vedada por algodão, para proceder-se a identificação e sexagem. Após a identificação, foram acondicionados em uma gaiola com armação metálica de alumínio e laterais de tule, com $91 \times 46 \times 46 \mathrm{~cm}$ de dimensão, depositada sobre suporte de madeira o qual possuia os pés imersos em potes plásticos com água e detergente, evitando assim, o acesso de ácaros, formigas, forídeos ou outros insetos à gaiola. Esta gaiola foi mantida na casa de criação anexa ao Departamento de Zoologia da Universidade Federal do Paraná, à temperatura ambiente. Estes adultos constituíram a geração parental.

Como substrato para alimentação e para postura, foi fornecida a região da cabeça de peixe (sardinha) em placas de Petri com $1,5 \mathrm{~cm}$ de altura por $9,0 \mathrm{~cm}$ de diâmetro. Em outra placa de Petri de igual dimensão, foi fornecido aos adultos um substrato de alimentação complementar, composto por uma mistura de açúcar, levedura de cerveja e leite em pó na proporção de 1:1:1 (modificado de LINHARES 1988). Água foi fornecida em frascos de vidro com $3,5 \mathrm{~cm}$ de altura por $4,0 \mathrm{~cm}$ de diâmetro, com substrato para pouso confeccionado em algodão.

Tanto a água quanto as dietas alimentares eram substituídas a cada 48 horas.

Os ovos obtidos das posturas da geração parental foram transferidos para cristalizadores de vidro com $15 \mathrm{~cm}$ de altura por $20 \mathrm{~cm}$ de diâmetro, recobertos com tule e contendo peixe como substrato alimentar para as larvas, até o final do terceiro ínstar, quando então era adicionada vermiculita, recobrindo todo o fundo dos cristalizadores, para otimizar a pupariação. Os adultos que emergiram destas pupas constituíram a geração F1, e serviram como fonte de material para este estudo. Estes foram transferidos para uma nova gaiola e mantidos nas mesmas condições da geração parental. Porém, o substrato de postura (cabeça de peixe) só lhes era fornecido quando havia a necessidade de obtenção de posturas. 


\section{ETAPA PRÉ-EXPERIMENTAL}

Foram realizadas quatro "criações piloto" antes de iniciar-se a etapa experimental propriamente dita, com o objetivo de: A) otimizar o delineamento do experimento, de maneira que se conseguisse extrair ao máximo as informações que as criações pudessem fornecer; B) praticar o manuseio de ovos e de larvas, assim evitando índices altos de inviabilidade de ovos e de mortalidade de larvas, que pudessem ser gerados pelo manuseio inadequado; C) eliminar ao máximo a interferência do observador; D) determinar a quantidade ideal de dieta por frasco que não interferisse no desenvolvimento larval e também o intervalo de tempo necessário entre uma troca de dieta e outra; E) determinar o número ideal de larvas por frasco para criação, sem que houvesse prejuízo para o desenvolvimento das formas imaturas, e que ao mesmo tempo se tornasse fácil e rápida a observação das larvas, para a determinação da duração dos ínstares; F) adquirir noção prévia da duração das diferentes fases do desenvolvimento ontogenético.

Destas criações piloto adotou-se o número de dez larvas por frasco como o ideal para o desenvolvimento larval e para comodidade de observação, minimizando assim, erros observacionais e a interferência demasiada no desenvolvimento do inseto. Determinou-se também, que a quantidade de dieta $(20 \mathrm{~g})$ seria suficiente para o desenvolvimento larval e não sendo um fator limitante no desenvolvimento das formas imaturas, desde que trocada a cada 48 horas.

\section{ETAPA EXPERIMENTAL}

\section{A) Ciclo evolutivo}

Duzentos ovos obtidos de uma das posturas da geração F1 foram individualizados, com auxílio de pincel fino, em solução de bisulfito de sódio $\left(\mathrm{NaHSO}_{3}\right)$ a $1 \%$, lavados em água destilada e acondicionados em 20 frascos plásticos (dez ovos por frasco) com $7,0 \mathrm{~cm}$ de altura por $4,0 \mathrm{~cm}$ de diâmetro, contendo $20 \mathrm{~g}$ de dieta artificial (LEAL et al. 1982) recobrindo todo o fundo do frasco. Na tampa destes frascos havia uma abertura com 1,5 por $1,5 \mathrm{~cm}$, revestida por tule para permitir a aeração e evitar a fuga das larvas ou a possível entrada de outros organismos.

Os frascos foram acondicionados em uma única bandeja, mantida na porção mediana da câmara de germinação Fanen modelo $347 \mathrm{CDC}$, à temperatura de $27 \pm 1^{\circ} \mathrm{C}$, umidade relativa do ar de $70 \pm 10 \%$ e fotofase de 12 horas.

A cada 48 horas, as larvas eram transferidas para novos frascos contendo dieta artificial fresca, mantendo-se a numeração dos frascos e suas posições originais na bandeja.

Próximo ao último dia do terceiro ínstar, as dietas eram substituídas por novas, as quais recobriam somente metade do fundo do frasco, sendo a outra metade recoberta por vermiculita, para que as larvas que se encontrassem na fase pós-alimentar (FRAENKEL \& BHASKARAN 1973) pudessem pupariar em local seco. Após a pupariação de todos os indivíduos, as pupas foram transferidas para frascos contendo somente vermiculita, mantendo-se a numeração e posição originais dos frascos na bandeja. 


\section{B) Longevidade dos adultos}

Para o estudo da longevidade dos adultos, foram formados 30 casais com indivíduos da mesma idade. Cada casal foi acondicionado em frasco de polietileno com $14,0 \mathrm{~cm}$ de altura por $13,0 \mathrm{~cm}$ de diâmetro e a abertura lateral coberta por tule.

Como alimento e substrato de postura foram fornecidos diariamente pedaços de peixe $(10 \mathrm{~g})$ em placas de Petri de $1,0 \mathrm{~cm}$ de altura $\times 5,0 \mathrm{~cm}$ de diâmetro e dieta alimentar suplementar composta de açúcar, leite em pó, levedura de cerveja (1:1:1) em placa de Petri, com as mesmas dimensões daquelas citadas acima. Água foi ofertada em frasco de vidro com $3,5 \mathrm{~cm}$ de altura por $4,0 \mathrm{~cm}$ de diâmetro, tendo algodão como substrato de pouso.

Os casais foram mantidos em câmara climatizada sob as mesmas condições ambientais indicadas anteriormente para as formas imaturas.

A medida que os adultos dos frascos morriam, o parceiro sobrevivente era transferido para um frasco onde houvesse vaga para aquele sexo, mantendo-se, sempre que possível, os casais formados até a morte de todos os adultos.

\section{C) Composição e preparo da dieta artificial}

A dieta artificial adotada foi descrita por LEAL et al. (1982), para criação de Chrysomya chloropyga (Wiedemann, 1818) [=putoria (Wiedemann, 1830)], e composta pelos seguintes ingredientes e proporções: leite em pó integral $(10,0 \mathrm{~g})$, levedura de cerveja em pó $(10,0 \mathrm{~g})$, caseína em pó $(0,5 \mathrm{~g})$, ágar em pó $(2,0 \mathrm{~g})$, "Nipagin" - Metil-P-Hidroxibenzenato - $(0,4 \mathrm{~g})$ e água destilada $(100,0 \mathrm{ml})$.

Para o preparo da dieta aquecia-se a água até o ponto de ebulição, esperava-se alguns minutos até a temperatura da água baixar para aproximadamente $80^{\circ} \mathrm{C}$, quando então era adicionado e dissolvido o ágar. Após este começar a tomar consistência gélica $\left(50^{\circ} \mathrm{C}\right)$, misturava-se o restante dos componentes da dieta. Este procedimento visou manter o valor protéico dos nutrientes da dieta, que poderia ser alterado em alta temperatura.

Após o preparo, a dieta era despejada diretamente nos frascos de criação, os quais eram imediatamente tampados, para evitar-se contaminação e desidratação da dieta, e em seguida acondicionados em refrigerador a aproximadamente $10^{\circ} \mathrm{C}$, até serem utilizados na criação, ou estocados aí por no máximo cinco dias. Antes de realizar-se a troca de meio, os frascos eram retirados do refrigerador e aclimatados durante quatro horas, na câmara climatizada a $27 \pm 1^{\circ} \mathrm{C}$. Após este período, procedia-se a mudança das larvas para os frascos com a nova dieta alimentar.

\section{D) Caracterização das fases do ciclo de vida}

Para a caracterização e determinação da duração das fases do ciclo de vida, foi realizado o acompanhamento do desenvolvimento dos indivíduos, principalmente através das seguintes modificações ocorridas nas diferentes fases do ciclo de vida: a) Período de incubação - determinado a partir do registro da data e hora da postura até o momento da eclosão das larvas; b) primeiro ínstar larval -determinado a partir da eclosão das larvas e caracterizado pela ausência de espiráculos anteriores e pela presença de uma única fenda nos espiráculos posteriores; c) segundo ínstar larval caracterizado pela presença de espiráculos anteriores e de duas fendas nos espiráculos posteriores; d) terceiro ínstar larval - caracterizado pela presença de três fendas 
nos espiráculos posteriores. O término deste ínstar foi considerado quando as larvas deixavam de alimentar-se e começavam a retração do corpo, isto é, formando o "pupário branco" (FRAENKEL \& BHASKARAN 1973); e) pré-pupa e pupa - o início da fase de pupa, abrangendo a de pré-pupa, foi determinada desde o momento da formação do "pupário branco" e posterior esclerotinização total do pupário até a emergência dos adultos; f) longevidade dos adultos - considerada desde a emergência até a morte espontânea destes. Durante o acompanhamento da longevidade dos adultos ainda foram determinados os períodos de pré-postura, postura e pós-postura, ou seja, o período compreendido entre a emergência e a primeira postura, período com posturas, e entre a última postura e a morte, respectivamente.

\section{D) Acompanhamento do ciclo de vida}

O acompanhamento do ciclo de vida de $S$. chlorogaster, foi realizado da seguinte maneira: a) 12 horas após a postura iniciavam-se observações a cada hora, até completar-se 24 horas da postura, para determinação do período de incubação; b) após a determinação do período anterior, iniciavam-se observações a cada seis horas para acompanhamento da duração do primeiro e segundo ínstares; c) observações a cada 12 horas para acompanhamento da duração do terceiro ínstar, do período pupal, e longevidade dos adultos. Sempre que possivel as larvas eram observadas sem a sua retirada do meio de cultura, exceto quando estas não encontravam-se nas laterais dos frascos, ou quando era efetuada a mudança da dieta.

O tempo anotado para a duração das diferentes fases do ciclo evolutivo de S. chlorogaster foi contado em relação a data e hora da postura, pois as larvas foram criadas em conjuntos de dez por frasco, o que não permitiu a visualização individualizada da mudança de ínstar. Assim para determinar-se a duração de cada ínstar, foi subtraído o valor da duração do tempo desde a postura até o estádio imediatamente anterior. Para determinar-se o tempo de duração do primeiro ínstar, por exemplo, o tempo decorrido desde a postura até o final do período de incubação, foi subtraído do valor da duração média do tempo decorrido desde a postura até o final do primeiro ínstar, e assim, sucessivamente para os demais ínstares, até a emergência dos adultos. O tempo de vida dos adultos foi considerado continuamente a partir da emergência, quando foram formados os casais emergidos na mesma data.

Neste estudo foi analisada somente a geração F2. Isto devido ao fato de a geração parental coletada na natureza, ainda não estar devidamente estabilizada às condições de cativeiro; também pelo fato da F2 ser progênie de uma geração (F1) inteiramente criada em condições laboratoriais (REIS et al. 1994); e ainda porque gerações acima da $\mathrm{F} 3$ podem começar a perder significativamente a variabilidade gênica, podendo assim, interferir nos resultados obtidos (Dr. Angelo Pires do Prado, comunicação pessoal).

\section{E) Confecção de tabelas de esperança de vida e de fertilidade}

$\mathrm{Na}$ construção das tabelas de esperança de vida, organizaram-se os parâmetros em colunas em função do intervalo etário de idade (x), por fase de desenvolvimento para imaturos e por semanas para adultos, segundo metodologia descrita por Silveira Neto et al. (1976), SoutHWood (1978) e RicKLEFS (1993).

A tabela de vida de fertilidade foi construída, segundo metodologia descrita 
por Silveira Neto et al. (1976), acrescentando-se três colunas extras: 1) número total de ovos (NTO); 2) número de fêmeas que ovipositaram $(\mathbf{F}) ; 3$ ) número médio de ovos entre as fêmeas que ovipositaram (NMO). Este procedimento visou facilitar o entendimento e cálculos de parâmetros da tabela, como fertilidade específica (mx). A probabilidade de sobrevivência no ponto médio do intervalo etário (lx), foi tomado a partir do valor de lx calculado para as formas imaturas na tabela de esperança de vida das formas imaturas.

\section{COLEÇÃO DE REFERÊNCIA}

Parte dos adultos que emergiram da criação em laboratório, foram sacrificados e montados em alfinete entomológico. Posteriormente foram depositados na Coleção Entomológica Pe. Jesus Santiago Moure, Departamento de Zoologia, Universidade Federal do Paraná.

\section{ANÁLISE ESTATISTICA}

Foram calculadas as médias ponderadas da duração de cada fase do ciclo de vida, seus desvios padrões e intervalos de confiança. Todas as médias obtidas foram comparadas quanto à sua homogeneidade, por teste de variância de médias (Teste F), ao nível de 0,05 de probabilidade. Quando as médias revelavam-se não homogêneas aplicava-se ainda o Teste de Tukey, também ao nível de 0,05 de probabilidade, com o objetivo de determinar-se qual ou quais das médias eram heterogêneas em relação ao conjunto de médias (VIEIRA 1981; VIEIRA \& HoFFMANN 1989).

Foram comparadas as médias do tempo de duração larval e da longevidade obtidas para machos e fêmeas, através do teste " $\mathrm{t}$ " de "Student", ao nível de 0,05 de probabilidade.

\section{RESULTADOS E DISCUSSÃO}

\section{ASPECTOS DO CICLO DE VIDA}

\section{Ciclo evolutivo}

Como pode ser observado na tabela I e figura 1, cada fase do ciclo evolutivo, apresentou uma duração gradualmente maior a medida que se desenrolava o desenvolvimento do inseto. A fase de incubação foi a mais curta com $3,04 \%(14,30$ horas) da duração do ciclo evolutivo, seguida pelo primeiro instar com 4,96\% $(23,34$ horas), segundo ínstar com 8,02\% (37,76 horas) e o terceiro ínstar com $35,17 \%$ ( 165,56 horas) da duração total do ciclo evolutivo. Por último, a fase ontogenética de pupa, a mais longa de todo o ciclo evolutivo com $48,81 \%$ (9,57 dias). O tempo total para o ciclo evolutivo, isto é, para o desenvolvimento de ovo a adulto, foi de 19,61 dias.

Dados e observações pormenorizados sobre cada fase do ciclo evolutivo, são apresentados na seqüência.

\section{Período de incubação}

A eclosão da larva de primeiro ínstar de $S$. chlorogaster ocorre através de movimentos de contração e expansão do corpo da larva no interior do ovo, o que faz com que este seja rompido por pressão exercida na região de sua linha de eclosão, sem o envolvimento aparente de estruturas especiais na larva para a eclosão. 
Tabela I. Duração do ciclo evolutivo de Sarconesia chlorogaster, sob condições de laboratório $\left(27 \pm 1^{\circ} \mathrm{C}, 70 \pm 10 \%\right.$ U.R., fotofase de $\left.12 \mathrm{~h}\right)$.

\begin{tabular}{ccccccc}
\hline \multirow{2}{*}{ Espécie } & \multirow{2}{*}{$\begin{array}{c}\text { Tempo médio de } \\
\text { Incubaçắ }(\mathrm{h})\end{array}$} & \multicolumn{3}{c}{ Duraçăo média das formas imaturas $(\mathrm{h})$} & \multicolumn{2}{c}{$\begin{array}{c}\text { Tempo total de } \\
\text { ovo a adulto (h) }\end{array}$} \\
\cline { 3 - 6 } & & Larva I & Larva II & Larva III & Pré-pupa+pupa & \\
\hline S. chlorogaster & 14,30 & 23,34 & 37,76 & 165,56 & 229,68 & 470,64 \\
\hline
\end{tabular}

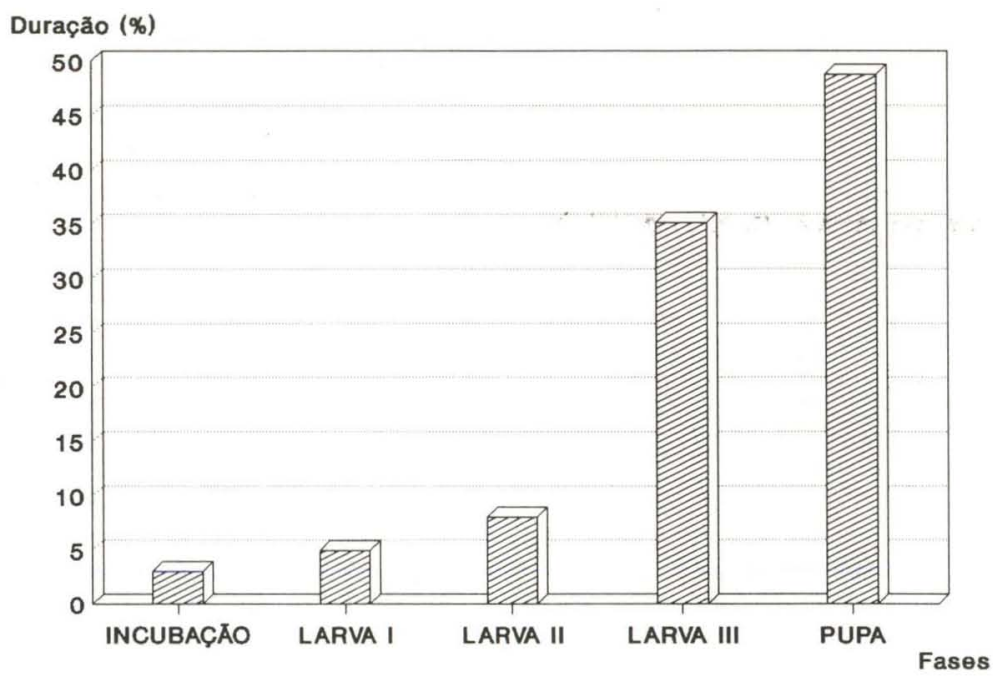

Fig. 1. Proporção entre a duração das fases do ciclo evolutivo de Sarconesia chlorogaster, $\left(27 \pm 1^{\circ} \mathrm{C}, 70 \pm 10 \%\right.$ U.R., $12 \mathrm{~h}$ de fotofase $)$.

Treze horas após a postura, as larvas de primeiro ínstar começavam a eclodir em pequeno número e grande parte dos ovos já encontravam-se embrionados. Porém, o pico de eclosão ocorreu entre 14 e 15 horas após a postura. Passadas dezesseis horas desde a postura todas as larvas já haviam eclodido dos 200 ovos em estudo, revelando um índice de fertilidade de 100\% (Fig. 2A). As médias de duração do período de incubação obtidas nos 20 frascos, não diferiram estatisticamente entre si e, portanto, considerou-se que o período de incubação para os ovos de $S$. chlorogaster durou em média 14,30 horas.

\section{Primeiro ínstar larval}

A medida que eclodiam, as larvas de primeiro ínstar permaneciam dispersas e locomovendo-se em várias direções, nitidamente procurando uma falha para penetrarem no meio de cultura. Na maioria dos casos, foi observado que a penetração no meio de cultura ocorria entre este e as paredes dos frascos de criação, região que provavelmente oferecia menor resistência à penetração. Assim que uma das larvas penetrava no meio de cultura, as demais faziam o mesmo na mesma região, mantendo-se agrupadas. 


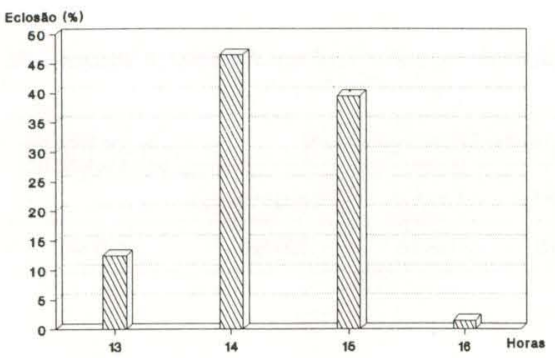

A

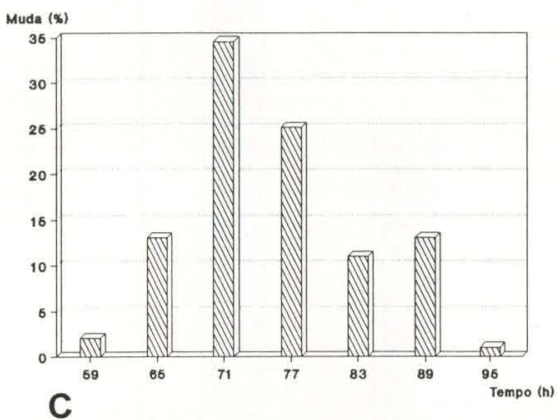

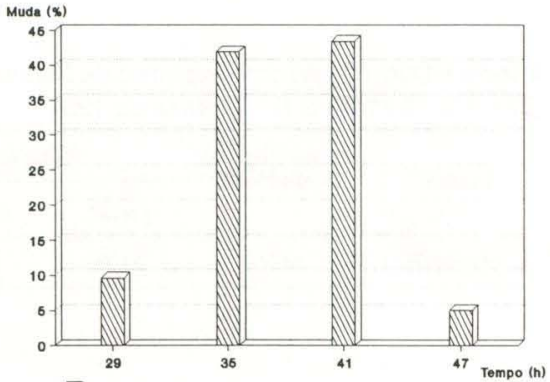

B

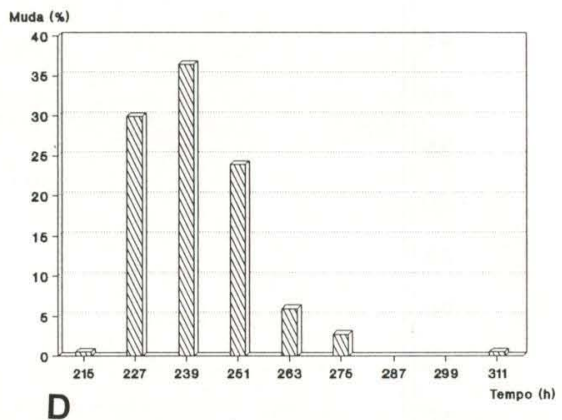

Fig. 2. Ciclo evolutivo de Sarconesia chlorogaster, a $27 \pm 1^{\circ} \mathrm{C}, 70 \pm 10 \%$ U.R., $12 \mathrm{~h}$ de fotofase. (A) Ritmo de eclosão das larvas de primeiro ínstar (incremento de uma hora, $n=200$ ); (B) ritmo de muda das larvas de primeiro para o segundo instar (incremento de seis horas, $n=198$ ); (C) ritmo de muda das larvas de segundo para o terceiro instar (incremento de seis horas, $n=191$ ); (D) ritmo de pupariação das larvas de terceiro instar (incremento de 12 horas, $n=184$ ).

Através da análise de variância das médias de duração deste ínstar, obtidas por frasco, constatou-se que algumas destas eram estatisticamente diferentes. Aplicando-se o teste de Tukey, observou-se a formação de dois grupos de médias, nos quais estas não diferiam entre si. As médias dos frascos número $6,10,12,14,15$, 17 e 19 foram reveladas como sendo as que formavam um dos grupos de médias estatisticamente iguais entre si. A formação deste grupo decorreu do fato das larvas dos frascos supra citados terem concluído o estádio de larva I em um tempo menor que as dos outros frascos, o que lhes conferiu médias mais baixas que as dos demais frascos.

A média global de duração do primeiro ínstar (considerando-se as médias obtidas nos 20 frascos), foi de 37,70 $\pm 4,45$ horas. Retirando-se os seis frascos supra citados da análise, foi obtida a duração média para o primeiro ínstar como sendo igual a 39,51 $\pm 3,50$ horas. Estas duas médias quando comparadas pelo teste " $t$ " de Student, demonstraram ser estatisticamente diferentes.

Acredita-se que o simples fato das médias dos frascos número $6,10,12,14$, 15,17 e 19 não serem estatisticamente iguais àquelas do outro grupo, não seja motivo suficiente para a retirada destes frascos da análise dos dados, tendo em vista que todos receberam o mesmo tratamento, ou seja, não há como inferir sobre a ação de agentes externos e também, descarta-se um provável erro de observação. Como 
esta anomalia mostrou-se presente somente nesta fase do ciclo de vida, acredita-se que possa ocorrer algum mecanismo genético atuando diferencialmente sobre alguns indivíduos nesta fase, ou ainda devido a fatores alimentares que possam agir diferencialmente sobre alguns indivíduos, acelerando o ciclo destes em determinada fase. Portanto, subtraindo-se o tempo médio do período de incubação (14,30 horas),

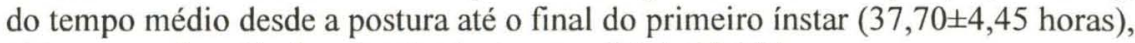
obteve-se a duração do primeiro ínstar, que foi de 23,40 horas.

$\mathrm{O}$ ritmo de passagem das larvas para o segundo ínstar, ocorreu de maneira sincrônica, ou seja, a maioria fazendo a muda em um curto intervalo de tempo, sendo que apenas seis horas foram necessárias para que $85,35 \%$ realizassem a muda (Fig. 2B).

\section{Segundo ínstar larval}

A exemplo das larvas de primeiro ínstar, as larvas deste estádio permaneceram agrupadas e submersas no meio de cultura, sempre mantendo a extremidade posterior voltada para cima, em busca de aeração. Este comportamento demonstra que certamente são os espiráculos posteriores, os principais responsáveis pela respiração das larvas. Embora permanecessem agrupadas, as larvas de segundo ínstar demonstraram ser mais ativas que as de primeiro ínstar, explorando maiores regiões do substrato alimentar. Além da maior mobilidade apresentada, observou-se que a alimentação ocorria de maneira mais intensa.

O tempo de duração do segundo ínstar larval demonstrou ser aproximadamente um terço maior que o primeiro ínstar. A análise de variância das médias de duração do segundo ínstar por frasco demonstrou que todas estas apresentavam-se de maneira homogênea. Portanto, subtraindo-se o tempo médio desde a postura até o final do primeiro instar (37,70 $\pm 4,45$ horas), do tempo médio desde a postura até o final do segundo ínstar ( $75,40 \pm 7,88$ horas), obteve-se a duração média do segundo ínstar larval, que foi de 37,70 horas, ou seja, 1,57 dias.

O ritmo de muda das larvas de segundo para o terceiro ínstar, ocorreu de maneira menos sincrônica do que do primeiro para o segundo ínstar, com uma sensível ampliação no intervalo de tempo para que houvesse a mudança de ínstar, ou seja, $100 \%$ maior (Fig. 2C).

\section{Terceiro ínstar larval}

Neste estádio as larvas encontravam-se mais dispersas pelo meio de cultura, não sendo mais observado, de maneira tão evidente, o comportamento de agrupamento. Igualmente ao que ocorreu nos ínstares anteriores, as larvas deste estádio mantinham a região posterior voltada para aberturas no substrato alimentar. A locomoção e a alimentação foram mais acentuadas, que nos ínstares anteriores. $\mathrm{Na}$ ausência de iluminação no interior da câmara de criação, as larvas podiam ser encontradas com facilidade na superfície do substrato alimentar. Próximo ao final deste ínstar, as larvas começavam a subir pelas paredes dos frascos com maior intensidade, certamente procurando um local com menos umidade para pupariar. Quando era observado este tipo de comportamento, mudava-se o meio de cultura por um em que a metade do fundo do frasco era recoberta pela dieta alimentar e a outra metade por vermiculita, procurando desta maneira favorecer a pupariação das larvas. 
Quanto à duração, o terceiro ínstar demonstrou ser o mais longo dos ínstares larvais. A análise de variância de médias revelou que não haviam diferenças estatisticamente significativas, entre as médias de duração deste ínstar obtidas por frasco. Portanto, subtraindo-se o tempo médio desde a postura até o final do segundo ínstar $(74,40 \pm 7,88$ horas), do tempo médio desde a postura até o final do terceiro ínstar $(240,96 \pm 13,25$ horas $)$, obteve-se a duração média do terceiro ínstar larval, que foi de 165,56 horas, ou seja, 6,90 dias.

O ritmo de pupariação foi o mais assincrônico, com uma amplitude de tempo para muda, muito mais elevada do que as demais mudas (Fig. 2D).

\section{Pré-pupa e pupa}

Assim que completado o terceiro ínstar, as larvas cessavam o processo alimentar e deixavam o meio de cultura em direção à vermiculita para pupariar.

Neste estudo considerou-se o estádio de pré-pupa em conjunto com a fase de pupa. Esta atitude foi tomada devido acreditar-se que o estádio de pré-pupa está mais intimamente relacionado com as modificações que ocorrem com a pupariação, do que relacionado com o terceiro ínstar larval, uma vez que a fase da pré-pupa é efêmera e caracteriza-se pela preparação do pupário, no interior do qual se dará a apólise larval, com a posterior formação da pupa (ZDAREK \& FRAENKEL 1972; FRAENKEL \& BHASKARAN 1973).

O início da fase de pré-pupa caracterizou-se pela supressão dos movimentos da larva, com posterior retração dos segmentos cefálico e primeiro torácico e formação do "pupário branco", que posteriormente torna-se marrom escuro e com consistência rígida, devido à esclerotinização do tegumento. Porém, a caracterização do final desta fase é de difícil visualização, pois envolve processos de apólises larval e pupal, que ocorrem no interior do pupário (FRAENKEL \& BHASKARAN 1973).

A fase de pupa foi a mais extensa do ciclo evolutivo de $S$. chlorogaster iniciando-se 215 horas após a postura e concluindo-se totalmente 539 após a postura, quando emergiu o último adulto. A análise de variância das médias de duração desta fase por frasco, demonstrou que estas poderiam ser tratadas como uma só, ou seja, as diferenças entre elas foram estatisticamente não significativas. Portanto, considerando-se que o tempo médio desde a postura até a emergência do último adulto, foi de $470,74 \pm 13,19$ horas e subtraindo-se deste valor a duração média desde a postura até o final do terceiro ínstar $(240,96 \pm 13,25$ horas), obteve-se a duração do período pupal que foi de 229,78 horas, ou seja, 9,57 dias.

\section{CONSIDERAÇÕES SOBRE O CICLO EVOLUTIVO}

Pouco se conhece sobre a biologia das espécies de Sarconesia Bigot, 1857. Com base nos resultados apresentados anteriormente são realizados a seguir, comentários e comparações com os principais dados existentes na literatura.

Em S. chlorogaster não existem estruturas morfológicas aparentemente ligadas à eclosão, entretanto, MARILUIS \& AVALOS (1987) discorrem sobre um espinho de eclosão, localizado dorsalmente, na larva de primeiro ínstar de $S$. magellanica (Le Guillou, 1842). Supostamente esta seria a única espécie do gênero que possuiria tal estrutura ( $c f$. GREENBERG \& SZYSKA 1984).

GREENBERG \& SZYSKA (1984) acompanharam o ciclo evolutivo de algumas 
espécies de Sarconesia, em condições ambientais não controladas com temperaturas médias diárias inferiores (oscilando entre 13,7 e $24,8^{\circ} \mathrm{C}$ ) a do presente estudo, e em meio de cultura natural composto de peixe ou fígado. Para $S$. chlorogaster observaram um período aproximado de 24-36 horas, 24-49 horas, 49-60 horas, 189-203 horas e 11-12 dias, respectivamente para o período de incubação dos ovos, primeiro, segundo, terceiro ínstares larvais e pré-pupa em conjunto com pupa; e como duração total do ciclo de ovo a adulto, obtiveram um período entre 23,1-25,5 dias. Neste mesmo trabalho GREENBERG \& SZYSKA (1984) obtiveram valores próximos aos mencionados acima para outras espécies do gênero, com exceção de uma criação efetuada posteriormente com S. versicolor Bigot, 1857, na qual os valores de duração dos estádios em geral foram mais baixos dos obtidos anteriormente. Este fato, como citam os autores, provavelmente foi devido à temperatura, pois para esta última criação a temperatura média foi mais elevada, oscilando entre $21,7 \mathrm{e} 29,5^{\circ} \mathrm{C}$. QUEIROZ et al. (1985) realizaram criação de $S$. chlorogaster semelhante à de GREENBERG \& SZYSKA (1984), porém com temperatura média de $25,5^{\circ} \mathrm{C}$ e observaram uma duração de aproximadamente 28 dias para o ciclo total.

Embora as espécies de Sarconesia estejam vinculadas à regiões de clima temperado a frio, geralmente, ocorre um desenvolvimento mais acelerado à temperaturas mais elevadas. Segundo Silveira Neto et al. (1976) e PARRA (1979) o desenvolvimento dos insetos está intimamente relacionado com a temperatura, pois quando há acréscimo de temperatura, estes organismos geralmente respondem com decréscimo no tempo de desenvolvimento, desde que os valores térmicos estejam próximos ao preferido destes.

BRYDON (1967) refere-se ao hábito de penetração no substrato alimentar como sendo comum em Fannia femoralis (Stein, 1898) (Diptera, Fanniidae). Segundo este autor as larvas respondem rápida e negativamente à luz procurando esconder-se. Provavelmente isto também seja verdadeiro para S. chlorogaster, além de poder estar relacionado a uma estratégia de proteção de predadores ou de agressões que possam vir a sofrer por prováveis variações bruscas do meio ambiente, além de certamente estar relacionado à alimentação. Outro fato que vem a corroborar a hipótese de BRYDON (1967) foi a constatação de que as larvas, na ausência de luminosidade (noite na câmara de criação), geralmente se encontravam na superfície do meio de cultura.

O comportamento de agrupamento apresentado pelas larvas, de $S$. chlorogaster, principalmente no primeiro e segundo ínstar, foi relatado pelo Dr. Angelo Pires do Prado (comunicação pessoal), como sendo comum entre várias espécies de Chrysomya Robineau-Desvoidy, 1830. Este agrupamento seria essencial para a transformação do meio de cultura e conseqüentemente para o pleno desenvolvimento larval. QUEIROZ \& MILWARD-DE-AZEVEDO (1991) referem-se a um comportamento de grupo para larvas de primeiro e segundo ínstar de Chrysomya albiceps (Wiedemann, 1819). GoODBROD \& GoFF (1990) observaram em populações de Chrysomya megacephala (Fabricius, 1794) do Havaí, que a temperatura do substrato de alimentação larval é superior a do ambiente em densidades larvais médias e altas, o que juntamente com as secreções de enzimas salivares e proteolíticas, aumentaria a eficiência do processo de alimentação larval e por conseguinte auxiliaria o seu desenvolvimento. 


\section{Tabela de esperança de vida e curva de sobrevivência das formas imaturas}

Sarconesia chlorogaster apr sentou um baixo índice de mortalidade das formas imaturas $(8,74 \%, n=200)$ (Tab. II). Foi observado que as larvas que avançavam muito além do tempo médio da duração do ínstar para efetuar a muda morriam.

A mortalidade no primeiro ínstar foi de apenas 1,00\% $(\mathrm{n}=200)$, correspondendo à morte de duas larvas. No segundo instar morreram $3,54 \%(n=198)$ das larvas, representados pela morte de sete larvas. O terceiro ínstar apresentou o mais elevado índice de mortalidade, $3,67 \%(n=191)$ representando a morte de sete larvas. $\mathrm{O}$ menor índice de mortalidade ocorreu na fase de pupa, onde somente uma pupa (0,54\%, $\mathrm{n}=184)$ foi inviável (Fig. 3).

Tabela II. Tabela de esperança de vida das formas imaturas de Sarconesia chlorogaster, por fases. Intervalo etário $(\mathrm{x})$ por fase; número de individuos sobreviventes no intervalo etário (Ix); número de indivíduos mortos no intervalo etário $(\mathrm{dx})$; número de indivíduos vivos entre um intervalo etário e outro $(L x)$; número total de indivíduos de idade $x$, além da idade $x(T x)$; esperança de vida para os individuos no intervalo etário (ex); razão de mortalidade por intervalo etário (qx).

\begin{tabular}{lcccccc}
\hline \multicolumn{1}{c}{$x$} & Ix & $\mathrm{dx}$ & Lx & Tx & ex & qx (\%) \\
\hline Ovo & 200 & 0 & 200,0 & 964,5 & 4,823 & 0,000 \\
Larva I & 200 & 2 & 199,0 & 764,5 & 3,823 & 1,000 \\
Larva II & 198 & 7 & 194,5 & 565,5 & 2,856 & 3,535 \\
Larva III & 191 & 7 & 187,5 & 371,0 & 1,942 & 3,665 \\
Pupa e pré-pupa & 184 & 1 & 183,5 & 183,5 & 0,997 & 0,543 \\
\hline
\end{tabular}

Analisando-se ainda a tabela II, pode ser observado que a esperança de vida para ovo, larvas de primeiro ínstar e pupas é muito superior à mortalidade, ocorrendo uma inversão desta expectativa para larvas de segundo e de terceiro ínstares, onde a expectativa de vida é menor, denotando uma dificuldade de desenvolvimento nestes ínstares. Estes dados contrastam com o observado por QUEIROZ et al. (1985). Segundo estes autores a mortalidade em $S$. chlorogaster seria mais acentuada nas fases de ovo e pupa. Acredita-se que estes autores chegaram a esta conclusão devido a prováveis falhas metodológicas quanto ao manuseio dos ovos no início de seu experimento, ocasionando um alto índice de inviabilidade e posteriormente as condições para pupariação das larvas provavelmente não foram adequadas às condições requeridas por este inseto. Outra hipótese a ser considerada, é o fato das condições ambientais utilizadas por estes autores não terem sido ideais ao desenvolvimento, fato eliminado na criação sob condições ambientais controladas e constantes do presente estudo.

A curva de sobrevivência para as formas imaturas de $S$. chlorogaster tende para o tipo III (SLOBODKIN 1962 apud SILVEIRA NeTO et al. 1976; SOUTHWOOD 1978), demonstrando haver uma fração relativamente constante de indivíduos que morrem a cada um dos intervalos de vida, ou seja, a medida que decorre o tempo a sobrevivência dos imaturos decresce (Fig. 3B). QUEIROZ et al. (1985) chegaram a este mesmo resultado. 


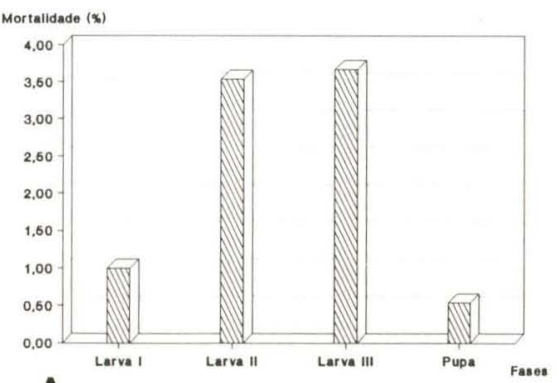

A

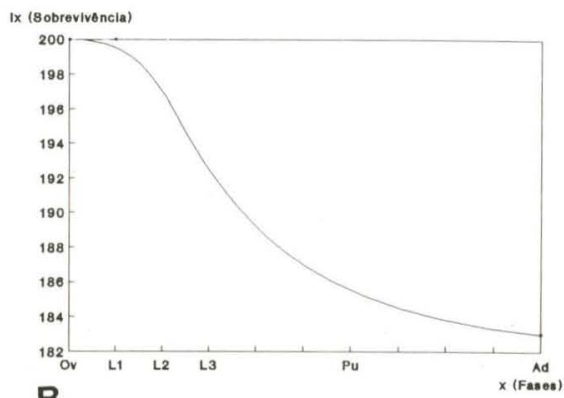

B

Fig. 3. Porcentagem de mortalidade (A) e curva de sobrevivência das formas imaturas de Sarconesia chlorogaster por fases. (Ix) Número de sobreviventes no intervalo etário; (x) intervalo etário (fases ontogenéticas); (Ov) ovos; (L1, L2 e L3) larva de primeiro, segundo e terceiro instar, respectivamente; ( $\mathrm{Pu}$ ) pré-pupa e pupa; $(\mathrm{Ad})$ adultos.

\section{LONGEVIDADE DOS ADULTOS}

A longevidade dos adultos, considerada desde a emergência até a morte espontânea destes, pode ser dividida em três períodos distintos: a) período de pré-postura, considerado a partir da emergência até a primeira postura; b) período de postura, considerado a partir da primeira até a última postura; c) período de pós-postura, compreendendo o tempo restante de vida desde a última postura até a morte do indivíduo (PARRA 1979; MALKOWSKI 1992). No estudo da longevidade dos adultos, as fêmeas dos frascos 19,25 e 30 foram retiradas das análises estatísticas que envolviam fertilidade dos adultos - duração dos períodos de pré-postura, postura, pós-postura e tabela de vida de fertilidade - pois, mesmo tendo copulado, estas fêmeas nunca ovipositaram. Porém, estas foram mantidas nos cálculos de longevidade média e tabela de vida dos adultos.

A longevidade média calculada para machos e fêmeas foi de 26,20 7,48 e $24,37 \pm 8,15$ dias respectivamente (Tab. III). A análise através do teste "t", revelou não haver diferença estatisticamente significativa entre estas médias ao nível de 0,05 de probabilidade, portanto, ambos os sexos apresentam a mesma longevidade sob as condicões deste experimento.

Particularidades de cada uma das fases da longevidade dos adultos são relatadas na seqüência.

\section{Ritmo de emergência de machos e fêmeas}

A emergência dos adultos iniciou-se 419 horas (17,46 dias) após a postura estendendo-se até 539 horas (22,46 dias) e em sua maioria ocorrendo à noite (Fig.4).

O tempo total médio de duração do ciclo evolutivo (ovo a adulto) para machos foi de 19,72 dias (473,26 10,45 horas) e para fêmeas foi de 19,51 dias $(468,19 \pm 15,19)$. Quando comparadas pelo teste " $t$ " de Student, estas médias revelaram ser estatisticamente diferentes ao nivel de $0,05 \%$ de probabilidade. Embora 
Tabela III. Mortalidade de adultos de Sarconesia chlorogaster criados sob condições de laboratório $\left(27 \pm 1^{\circ} \mathrm{C}, 70 \pm 10 \%\right.$ U.R., fotofase de $\left.12 \mathrm{~h}\right)$. Longevidade média (LON); desvio padrão (s); intervalo de confiança (I.C.).

\begin{tabular}{cccc}
\hline Tempo & Machos & Fêmeas & Total \\
\hline $0-7$ & - & - & - \\
$7-14$ & - & 1 & 1 \\
$14-21$ & 8 & 10 & 16 \\
$21-28$ & 8 & 9 & 17 \\
$28-35$ & 11 & 4 & 15 \\
$35-42$ & 5 & 6 & 11 \\
\hline Total & 30 & 30 & 60 \\
LON & $26,20 a$ & 24,37 a & 25,28 a \\
S & 7,48 & 8,15 & 7,81 \\
I.C. & 2,79 & 3,04 & 2,02
\end{tabular}

*. Tempo em dias contado desde a emergência. Valores seguidos da mesma letra, não diferem estatisticamente ao nivel de 0,05 de probabilidade.

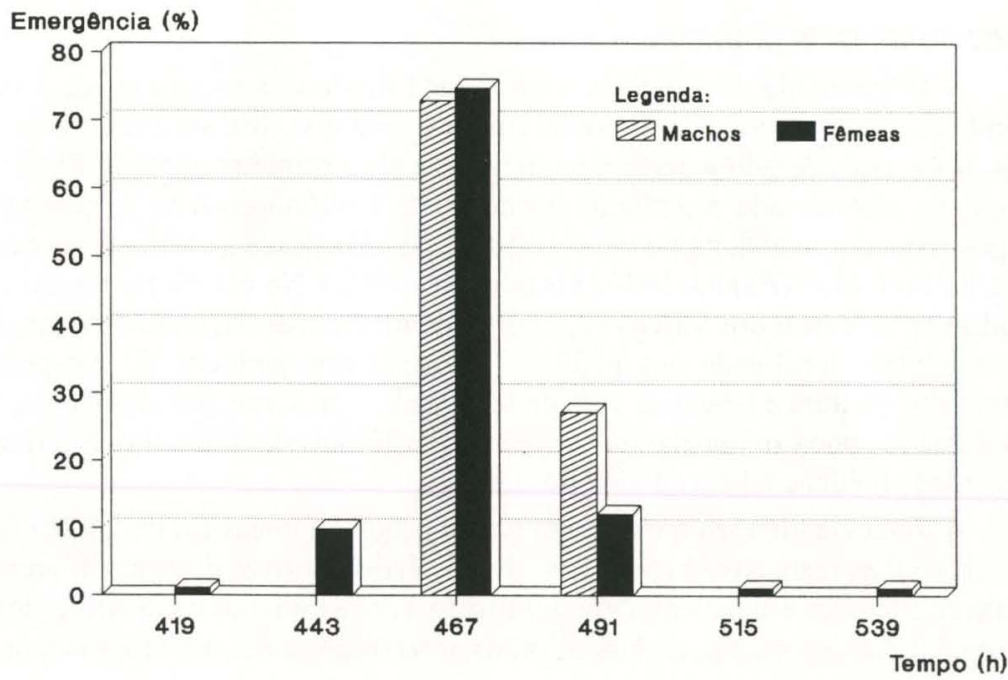

Fig. 4. Ritmo de emergência de machos e fêmeas de Sarconesia chlorogaster, $\left(27 \pm 1^{\circ} \mathrm{C}\right.$, $70 \pm 10 \%$ U.R., $12 \mathrm{~h}$ de fotofase). Incremento de 24 horas, $\mathrm{n}=183$.

os valores das médias estejam muito próximos - apenas cinco horas de diferença entre machos e fêmeas - acredita-se que realmente o ciclo evolutivo das fềmeas se realize em um período de tempo mais curto, uma vez que em todas as criações realizadas (criação dos estoques, pré-experimental e experimental), as fêmeas sempre emergiram antes dos machos. Entretanto, como pode ser observado na figura 4, a amplitude do tempo de emergência para as fềmeas é maior, embora estas tenham começado a emergir dois dias antes dos machos e tendo concluído a emergência 
dois dias depois destes, levando ao todo seis dias para a emergência de todas as fêmeas; já os machos realizaram a emergência no período de somente dois dias.

A razão de sexos calculada foi de 0,497 fêmeas e 0,503 machos e como não houve diferença estatisticamente significativa ao nível de 0,05 de probabilidade, pode-se considerar a proporção de sexos de $S$. chlorogaster como sendo de 1:1. Em experimento com Chrysomya albiceps (Wiedemann, 1819) QUEIROZ \& MILWARDDE-AZEVEDO (1991), concluíram que as fêmeas desta espécie emergem antes dos machos, ou seja, que o ciclo evolutivo das fêmeas é mais curto que o dos machos, e que a razão de sexos nesta espécie, também é de 1:1, resultados semelhantes aos obtidos no presente estudo.

\section{Período de pré-postura}

O período de pré-postura revelou ser pouco menos extenso que o período de postura, tendo uma duração média de $8,41 \pm 1,91$ dias (Tab. IV).

Durante esta fase pôde ser observado um período característico de pré-cópula, tempo desde a emergência até a primeira cópula, que estendeu-se até o quinto dia depois da emergência, quando começaram a ocorrer as primeiras cópulas. $\mathrm{O}$ fato de ocorrerem cópulas somente após cinco ou seis dias e de maneira relativamente sincronizada, provavelmente esteja correlacionada com o amadurecimento sexual das fêmeas, embora CHAPMAN (1975) acredite que a estimulação das fêmeas à cópula, não esteja necessariamente relacionada ao amadurecimento dos oócitos.

Houve uma nítida concentração de cópulas entre o quinto e $11^{\circ}$ dias após a emergência, havendo uma gradual diminuição das cópulas com o decorrer do tempo. Porém, em alguns casais, a cópula pôde ser observada até os últimos dias de vida, diferindo do que ocorre com algumas espécies de Diptera, onde a fêmea permite somente uma cópula durante a vida (KRAFSUR \& ERNEST 1983), ou outras em que a fêmea rejeita a cópula por determinado período após a primeira cópula (SMITH et al. 1989).

\section{Período de postura}

O período de postura teve início entre o oitavo e nono dias após a emergência, quando foram observadas as primeiras posturas para a maioria das fêmeas estudadas, sendo que a sua duração média foi de 10,96 $\pm 6,55$ dias (Tab. IV). Diferentemente do que ocorreu com as cópulas, as posturas foram mais esparsas, fato que tornou difícil a caracterização do período de postura.

Tabela IV. Duração média, em dias, dos periodos de pré-postura, postura e pós-postura (X) de Sarconesia chlorogaster, obtidas da criação de 30 casais, sob condições ambientais controladas $\left(27 \pm 1^{\circ} \mathrm{C}\right.$, U.R. $70 \pm 10 \%$, fotofase de 12 horas). Desvio padrão (s); intervalo de confiança (I.C.).

\begin{tabular}{rccc}
\hline & Pré-potura & Postura & Pós-postura \\
\hline $\bar{X}$ & $8,41 \mathrm{a}$ & $10,96 \mathrm{a}$ & $5,15 \mathrm{~b}$ \\
$\mathrm{~S}$ & 1,91 & 6,55 & 4,37 \\
I.C. & 0,75 & 2,59 & 1,73 \\
\hline
\end{tabular}

*. Valores seguidos da mesma letra, não diferem estatisticamente ao nivel de 0,05 de probabilidade. 
Como ocorre com fêmeas anautógenas de muitos Diptera, ou seja, que necessitam de uma alimentação protéica para desenvolver seus folículos ovarianos (CHAPMAN 1975), S. chlorogaster somente inicia a oviposição após determinado período de alimentação a base de proteína animal. O tempo entre oito e nove dias para ocorrência das primeiras posturas, está em concordância com os dados obtidos por AVANCINI (1986) e LiNHARES (1988) para diferentes espécies de Calliphoridae, onde o primeiro ciclo gonadotrófico estaria concluído, em média, até o nono dia após a emergência, quando então as fềmeas estariam aptas a ovipositar.

Ao todo foram constatadas 68 posturas com um total de 7825 ovos, o que conferiu às fêmeas uma fecundidade média de $115,07 \pm 1,42$ ovos por postura (Tab. V). O número mínimo de posturas por fêmea foi de uma e o máximo de cinco posturas, com exceção das três fêmeas dos frascos 19, 25, 30 que nunca ovipositaram, embora tivessem copulado duas ou mais vezes. Assim, entre as 27 fêmeas que ovipositaram normalmente, foi obtido o número médio de posturas por fêmea de $2,52 \pm 1,22$ posturas. A faita de homogeneidade entre o número de posturas por fềmea - número de posturas variando entre uma a cinco posturas - provavelmente foi ocasionada devido à falta de condições ideais para a postura, ou à formação de casais com possível falta de afinidade entre si, embora tenham sido formados ao acaso, ou ainda, a uma inaptidão natural a ovipositar de algumas fêmeas que não ovipositaram ou o fizeram somente uma ou duas vezes.

Tabela V. Número de ovos por postura por fêmea de Sarconesia chlorogaster, criadas sob condições de laboratório $\left(27 \pm 1^{\circ} \mathrm{C}, 70 \pm 10 \%\right.$ U.R. e fotofase de $12 \mathrm{~h}$.)

\begin{tabular}{|c|c|c|c|c|c|c|c|c|c|c|c|c|c|c|c|c|}
\hline Postura Fêmea & 1 & 2 & 3 & 4 & 5 & 6 & 7 & 8 & 9 & 10 & 11 & 12 & 13 & 14 & 15 & 16 \\
\hline 1 & 152 & 141 & 134 & 158 & 153 & 147 & 117 & 122 & 90 & 194 & 150 & 142 & 99 & 140 & 80 & 128 \\
\hline 2 & 62 & 47 & 130 & - & 160 & - & 89 & 36 & 121 & 77 & 165 & 116 & 78 & 29 & 78 & 148 \\
\hline 3 & 104 & - & - & - & 145 & - & 113 & 117 & - & -127 & 86 & 58 & - & - & - & . \\
\hline 4 & - & - & - & - & 127 & - & - & - & - & -66 & - & 92 & - & - & - & . \\
\hline 5 & - & - & - & - & - & - & - & - & - & - & - & 60 & - & - & - & . \\
\hline Total & 318 & 188 & 264 & 158 & 585 & 147 & 319 & 275 & 211 & 464 & 401 & 468 & 177 & 169 & 158 & 276 \\
\hline $\begin{array}{l}\text { Fêmea } \\
\text { Postura }\end{array}$ & 17 & 18 & 19 & 20 & 21 & 22 & 23 & 24 & 25 & 26 & 27 & 28 & 29 & 30 & To & tal \\
\hline 1 & 189 & 149 & - & -121 & 195 & 46 & 108 & 149 & - & -153 & 184 & 126 & 168 & - & & 735 \\
\hline 2 & 123 & 166 & - & -132 & 104 & 93 & 152 & - & - & -115 & 118 & 55 & - & - & & 394 \\
\hline 3 & - & 10 & - & -114 & - & - & 136 & - & - & - & - 58 & - & - & - & & 068 \\
\hline 4 & - & - & - & - 87 & - & - & 74 & - & - & - & - & - & - & - & & 446 \\
\hline 5 & - & - & - & - & - & - & 122 & - & - & - & - & - & - & - & & 182 \\
\hline Total & 312 & 325 & - & -454 & 299 & 139 & 592 & 149 & - & -268 & 360 & 181 & 168 & - & & 825 \\
\hline
\end{tabular}

\section{Período de pós-postura}

Na tentativa de caracterização do período de pós-postura, foram anotados os intervalos de tempo entre a última postura e a morte espontânea para cada fêmea e calculado o tempo médio total deste período, que foi de $5,15 \pm 4,37$ dias, sendo o de mais curta duração dos três períodos durante o acompanhamento da longevidade dos adultos (Tab. IV). O alto valor do desvio padrão, igualando-se praticamente à 
média, revela que houve uma variação muito grande na duração do período de pós-postura, o que não o caracteriza de maneira tão evidente quanto os períodos de pré-postura e de postura. Entretanto, como há uma tendência das fêmeas morrerem logo após a última postura, torna-se evidente que este seja realmente, o mais curto período durante a longevidade das fềmeas desta espécie.

\section{Tabela de esperança de vida e curva de sobrevivência dos adultos}

Nas tabelas VI e VII estão representadas as tabelas de esperança de vida para machos e fêmeas de S. chlorogaster, respectivamente. Como pode ser observado os valores de $\mathrm{lx}$, Lx e Tx são gradativos tanto para machos quanto para fêmeas. Porém, os valores de qx possuem segmentos distintos, sendo que a porcentagem de mortalidade por intervalo etário para fêmeas sempre foi mais elevado, com exceção da penúltima semana de vida, quando a mortalidade de machos é maior. Assim sendo, a esperança de vida para os machos sempre foi superior à das fêmeas, demonstrando que até a quarta semana de vida dos adultos de $S$. chlorogaster, a expectativa de vida dos machos é superior à das fêmeas. Entretanto, as fêmeas que conseguiram chegar até quinta semana de vida, possuem uma esperança de vida maior que os machos neste intervalo etário.

Tabela VI. Tabela de esperança de vida de machos de Sarconesia chlorogaster, por semana. Intervalo etário $(x)$; número de individuos sobreviventes no intervalo etário (Ix); número de indivíduos mortos no intervalo etário $(\mathrm{dx})$; número de indivíduos vivos entre um intervalo etário e outro ( $L x)$; número total de indivíduos de idade $x$, além da idade $x(T x)$; esperança de vida para os indivíduos no intervalo etário (ex); razão de mortalidade por intervalo etário (qx).

\begin{tabular}{ccrrrrr}
\hline $\mathrm{x}$ (dias) & $\mathrm{Ix}$ & $\mathrm{dx}$ & $\mathrm{Lx}$ & \multicolumn{1}{c}{$\mathrm{Tx}$} & $\mathrm{ex}$ & $\mathrm{qx}(\%)$ \\
\hline $0-7$ & 30 & 0 & 30,0 & 120,0 & 4,000 & 0,00 \\
$7-14$ & 30 & 0 & 30,0 & 90,0 & 3,000 & 0,00 \\
$14-21$ & 30 & 6 & 27,0 & 60,0 & 2,000 & 20,00 \\
$21-28$ & 24 & 8 & 20,0 & 33,0 & 1,375 & 33,33 \\
$28-35$ & 16 & 11 & 10,5 & 13,0 & 0,813 & 68,75 \\
$35-42$ & 5 & 5 & 2,5 & 2,5 & 0,500 & 100,00 \\
\hline
\end{tabular}

Tabela VII. Tabela de esperança de vida de fêmeas de Sarconesia chlorogaster, por semana. Intervalo etário $(\mathrm{x})$; número de indivíduos sobreviventes no intervalo etário (Ix); número de individuos mortos no intervalo etário $(\mathrm{dx})$; número de indivíduos vivos entre um intervalo etário e outro ( $L x)$; número total de indivíduos de idade $x$, além da idade $x(T x)$; esperança de vida para os indivíduos no intervalo etário (ex); razão de mortalidade por intervalo etário (qx).

\begin{tabular}{crrrrrr}
\hline$x$ (dias) & Ix & dex & \multicolumn{1}{c}{ Lx } & \multicolumn{1}{c}{ Tx } & \multicolumn{1}{c}{ ex } & \multicolumn{1}{c}{$\mathrm{qx}(\%)$} \\
\hline $0-7$ & 30 & 0 & 30,0 & 109,0 & 3,633 & 0,00 \\
$7-14$ & 30 & 1 & 29,5 & 79,0 & 2,633 & 3,33 \\
$14-21$ & 29 & 10 & 24,0 & 49,5 & 1.707 & 34,48 \\
$21-28$ & 19 & 9 & 14,5 & 25,5 & 1,342 & 47,37 \\
$28-35$ & 10 & 4 & 8,0 & 11,0 & 1,100 & 40,00 \\
$35-42$ & 6 & 6 & 3,0 & 3,0 & 0,500 & 100,00 \\
\hline
\end{tabular}


As curvas de sobrevivência para machos e fêmeas, estão representadas na figura 5. Tanto a sobrevivência de machos quanto a de fêmeas de $S$. chlorogaster, manteve-se constante até a terceira semana de vida. A medida que decorre o tempo, a partir da terceira semana, há um decréscimo na sobrevivência de ambos os sexos, sendo mais acentuado para as fêmeas (Fig. 5). Com base nestas características da sobrevivência, tornou-se difícil a caracterização do tipo de curva de sobrevivência para os adultos de S. chlorogaster; uma vez que até a terceira semana de vida a curva de sobrevivência tende para o tipo I, porém a partir deste ponto, há uma tendência para uma curva do tipo II ou III, dificuldade esta acrescida pelo fato de a caracterização das curvas de sobrevivência proposta por SILVEIRA NETO et al. (1976), ser essencialmente visual.

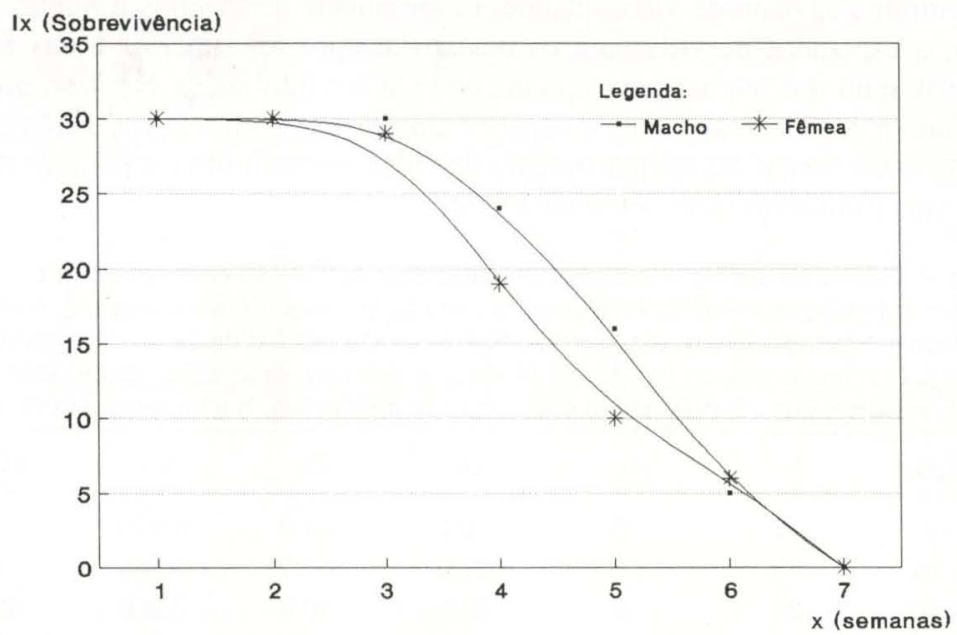

Fig. 5. Curvas de sobrevivências de machos e fêmeas de Sarconesia chlorogaster, por semana. (Ix) Número de sobreviventes no intervalo etário, $(x)$ intervalo etário em semanas.

\section{Tabela de vida de fertilidade}

Para uma melhor avaliação da influência das condições laboratoriais, aplicadas no presente estudo, no desenvolvimento de $S$. chlorogaster foi elaborada, pela primeira vez, a tabela de fertilidade para esta espécie (Tab. VIII).

A taxa líquida de reprodução (Ro), isto é, o número de vezes que a população aumenta a cada geração, foi de 133,29 vezes; a duração média de uma geração (T), foi de 5,30 semanas; a capacidade inata de aumentar em número (rm), ou seja, a taxa intrínseca de crescimento natural, foi de 0,92 ; o número de indivíduos fêmeas adicionados à população, por fêmea e por semana $(\lambda)$, foi de 2,50 fêmeas por semana, de tal forma que o número de fêmeas adicionadas à população, numa geração $\left(\lambda^{T}\right)$, é de 128,53 fêmeas. Como um ano possui 52 semanas e cada geração de $S$. chlorogaster dura aproximadamente 5,30 semanas sob estas condições de criação, o número esperado de gerações desta espécie é de aproximadamente 9,81 gerações ao ano. 
Tabela VIII. Tabela de vida de fertilidade de Sarconesia chlorogaster, por semana. Intervalo etário (x); número total de ovos ovipositados no intervalo etário (NTO); fêmeas vivas no intervalo etário que ovipositaram ( $F$ ); número médio de ovos por fêmea (NMO); número de ovos por fêmea por semana e que darão fêmeas $(\mathrm{mx})$; probabilidade de sobrevivência no ponto médio (Ix).

\begin{tabular}{ccccccccc}
\hline$x$ (semana) & NTO & $F$ & NMO & $m x$ & $\mathrm{Ix}$ & $\mathrm{mx} . \mathrm{Ix}$ & $\mathrm{mx} . \mathrm{lx} . x$ & Fases \\
\hline 0,5 & - & - & - & - & - & - & - & Ovo, larva \\
1,5 & - & - & - & - & - & - & - & e pupa \\
2,5 & - & - & - & - & 0,92 & - & - & \\
\hline 3,5 & - & $27^{\star}$ & - & - & 0,92 & - & - & \\
4,5 & 3630 & 27 & 134,44 & 67,22 & 0,92 & 61,84 & 278,28 & \\
5,5 & 2572 & 18 & 142,89 & 71,45 & 0,61 & 43,58 & 239,69 & Adulto \\
6,5 & 1228 & 9 & 136,44 & 68,22 & 0,31 & 21,15 & 137,48 & \\
7,5 & 395 & 5 & 79,00 & 39,50 & 0,17 & 6,72 & 50,40 & \\
\hline$\Sigma$ & & & & & & 133,29 & 705,85 & \\
\hline
\end{tabular}

*. Consideradas somente as fêmeas que realizaram no minimo uma postura durante a vida.

O potencial biótico, ou a capacidade inerente do indivíduo de se reproduzir e sobreviver, está na dependência do potencial de reprodução e da resistência do ambiente (Silveira NeTo et al. 1976). Como a resistência do ambiente sob condições de laboratório é praticamente nula, o potencial biótico de $S$. chlorogaster, no presente estudo foi estimado a partir do potencial de reprodução.

O potencial de reprodução ( $\mathrm{Pr}$ ), ou seja, a velocidade na qual um indivíduo é capaz de se reproduzir (SILVEIRA NETO et al. 1976), foi estimado em 1,74×10 indivíduos por ano, sob as condições deste experimento. Este alto índice de reprodução apresentado por $S$. chlorogaster certamente é muito inferior na natureza, uma vez que a resistência do meio ambiente deve ser muito elevada e ocasionada, por exemplo, pela temperatura oscilante, predadores, acesso e competição intra e inter-específica à fontes nutritivas, entre outros fatores. Porém, todos os valores calculados a partir da tabela de vida de fertilidade, servem como parâmetros para futuros estudos.

Como estudos desta natureza nunca foram realizados com esta espécie, os parâmetros obtidos no momento caracterizam somente as condições experimentais empregadas neste estudo, porém, certamente servirão para a comparação com estudos futuros. Entretanto, pode-se afirmar, pelos resultados apresentados na tabela VIII, que as condições ambientais e nutricionais aplicadas aqui, são adequadas para o pleno desenvolvimento desta espécie em laboratório.

\section{CONCLUSÕES}

A eclosão das larvas de primeiro ínstar ocorre por pressão, exercida sobre a linha de eclosão no cório, causada por contrações e expansões do corpo da larva, sem o envolvimento de estruturas especiais para a eclosão.

O ciclo evolutivo de Sarconesia chlorögaster é de aproximadamente 20 dias, sob as condições experimentais de $27 \pm 1^{\circ} \mathrm{C}, 70 \pm 10 \%$ U.R. e 12 horas de fotofase, porém, o ciclo evolutivo de fêmeas é mais curto que o dos machos. 
$\mathrm{O}$ ciclo de vida desta espécie, quando criada à $27 \pm 1^{\circ} \mathrm{C}, 70 \pm 10 \%$ U.R. e 12 horas de fotofase, é de aproximadamente 45 dias, não havendo diferença estatisticamente significativa entre a duração do ciclo de vida de machos e fêmeas.

Há um gradual aumento na duração de cada fase ontogenética a medida que o desenvolvimento avança, sendo o período de incubação o mais curto e o período pupal o mais extenso do ciclo evolutivo.

As larvas de primeiro e segundo ínstar apresentam um comportamento de agrupamento acentuado, relacionado com a transformação do meio de cultura para a alimentação.

A curva de sobrevivência para as formas imaturas tende para o tipo III, havendo um decréscimo na expectativa de vida a medida que decorre o tempo de desenvolvimento.

As fềmeas emergem predominantemente antes dos machos. Entretanto, machos e fêmeas possuem a mesma longevidade.

A proporção de machos e fêmeas é de 1:1.

As condições experimentais empregadas, são adequadas para a criação desta espécie em laboratório, revelando baixos índices de mortalidade e altos valores de fertilidade e fecundidade.

AGRADECIMENTOS. Ao Conselho Nacional de Desenvolvimento Científico e Tecnológico (CNPq) pela concessão da Bolsa de Mestrado. Ao Prof. Dr. Claudio José Barros de Carvalho (Departamento de Zoologia da Universidade Federal do Paraná - DZUP/UFPR) pela orientação, sugestões, críticas e bibliografia concedida. Aos professores Dr. Renato Contin Marinoni e Dra. Luciane Marinoni (ambos do DZUP/UFPR), pelas sugestões e críticas na elaboração e delineamento do experimento e pelo empréstimo de bibliografia e equipamento. Aos professores Dr. Ângelo Pires do Prado (Departamento de Parasitologia da Universidade Estadual de Campinas), Dr. Zundir José Buzzi e MSc. Marcelo José Aranha (ambos do DZUP/UFPR) pelas discussões e críticas dos dados de biologia. Ao Pesquisador Dr. Edilson de Oliveira (Empresa Brasileira de Pesquisa Agropecuária, Colombo, Paraná) pelas sugestões e críticas na parte estatística deste trabalho.

\section{REFERÊNCIAS BIBLIOGRÁFICAS}

Avancini, R.M.P. 1986. Fases de desenvolvimento ovariano em seis espécies de Calliphoridae (Diptera). Revta bras. Ent. 30 (2): 359-364.

Baumgartner, D.L. \& B. GreenBerg. 1985. Distribution and medical ecology of the blow flies (Diptera: Calliphoridae) of Peru. Ann. Entomol. Soc. Amer. 78 (5): 565-587.

BRYDON, H.W. 1967. Response of larval Fannia femoralis (Diptera, Anthomyiidae) to light. Ann. Entomol. Soc. Amer. 60 (2): 478-480.

CHAPMAN, R.F. 1975. The insects: structure and function. London, The English Universities Press Ltd, 2nd ed., XII+819p.

Dear, J.P. 1979. A revision of the Toxotarsinae (Diptera: Calliphoridae). Pap. Avulsos Dept. Zool., São Paulo, 32 (13): 145-182. 
FerReira, M.J. DE M. 1978. Sinantropia de dípteros muscóideos de Curitiba,

Paraná. I. Calliphoridae. Revta Bras. Biol. 38 (2): 445-454.

Fraenkel, G. \& G. Bhaskaran. 1973. Pupariation and Pupation in Cyclorrhaphous Flies (Diptera): Terminology and Interpretation. Ann. Entomol. Soc. Amer. 66 (2): 418-422.

FurlanetTo, S.M.P.; M.L. CAMPOS \& C.M. HÁRSI. 1984. Microoragismos enteropa- togênicos em moscas africanas pertencentes ao gênero Chrysomya (Diptera: Calliphoridae) no Brasil. Rev. Microbiol. 15 (3): 170-174.

GoodBRoD, J.R. \& M.L. GoFf. 1990. Effects of larval population density of development and interactions between two species of Chrysomya (Diptera: Calliphoridae) in laboratory culture. J. Med. Entomol. 27: 338-343.

GreENBERG, B. 1971. Flies and disease. Ecology, classification and biotic associations. New Jersey, Princeton University Press, Volume 1, VII+586p.

GREENBERG, B. \& M.L. SzYSKA. 1984. Immature stages and biology of fifteen species of Peruvian Calliphoridae (Diptera). Ann. Entomol. Soc. Amer. 77 (5): 488-517.

Guimarães, J.H.; N. PaPAVERo \& A.P.Do Prado. 1983. As miíases na Região Neotropical (identificação, biologia, bibliografia). Revta bras. Zool. 1 (4): 239-416.

Krafsur, E.S. \& C.M. ERNEST. 1983. Physiological age composition and reproductive biology of horn fly populations, Haematobia irritans (Diptera: Muscidae) in Iowa, USA. J. Med. Entomol. 20: 664-669.

LEAL, T.T. DE S.; A.P. Do PRADO; A.J. ANTUNES. 1982. Rearing the larvae of the blowfly Chrysomya chloropyga (Wiedemann) (Diptera: Calliphoridae) on ologidic diets. Revta bras. Zool. 1 (1): 41-44.

LINHARES, A.X. 1988. The gonotrophic cycle of Chrysomya megacephala (Diptera, Calliphoridae) in the laboratory. Revta bras. Ent. 32 (3/4): 383-392.

Lopes, H. DE S. \& D. DE O. Albuquerque. 1982. Notes on Neotropical Calliphoridae (Diptera). Rev. Bras. Biol. 42 (1): 63-69.

MALKOWSKI, S.R. 1992. Aspectos morfológicos da larva de terceiro ínstar e ciclo de vida de Fannia trimaculata (Stein, 1898) e Fannia femoralis (Stein, 1898) (Diptera, Fanniidae). Tese de Mestrado, não publicada, Universidade Federal do Paraná,Curitiba, IX+63p.

MARILUIS, J.C. 1982. Contribucion al conocimiento de las Calliphoridae de la Argentina (Insecta: Diptera). Opera Lilloana 33: 1-59.

MARILUIS, J.C. \& D.S. AVALOS. 1987. Contribucion al conocimiento de los estadios del desarrollo de Sarconesiops magellanica (Le Guillou, 1842) (Diptera, Calliphoridae, Toxotarsinae). Rev. Soc. Entomol. Argent. 44 (3-4): 353-356.

Mariluis, J.C.; M.C. Lagar \& E.J. Bellegarde. 1989. Diseminacion de enteroparasitos por Calliphoridae (Insecta: Diptera). Mem. Inst. Oswaldo Cruz, Rio de Janeiro, 84 (Supl. IV): 349-351.

MELLO, R.P DE. 1972. Contribuição ao estudo do gênero Sarconesia Bigot, 1857 (Diptera: Calliphoridae). Rev. Bras. Biol. 32 (4): 533-537.

PARRA, J.R.P. 1979. Biologia dos insetos. Piracicaba, Universidade de São Paulo 
- Escola Superior de Agricultura "Luiz de Queiroz", não publicado, mimeografado, 383p.

QueIroz, M.M. DE C. \& E.M.V. Milward-De-Azevedo. 1991. Técnicas de criação e alguns aspectos da biologia de Chrysomya albiceps (Wiedemann) (Diptera, Calliphoridae), em condições de laboratório. Revta bras. Zool. 8 (1/2/3/4): 75-84.

Queiroz, S.M.P.; J.R. DE Almeida; C.J.B. DE Carvalho \& L. Dudas. 1985. Bionomia de Sarconesia chlorogaster (Wiedemann, 1830) em Curitiba, Paraná, Brasil. An. Soc. Entomol. Bras. 14 (1): 105-110.

Reis, S.F. dos; G. Stangenhaus; W.A.C. Godoy; C.J. von Zuben \& O.B. RIBEIRO. 1994. Variação em caracteres bionômicos em função de densidade larval em Chrysomya megacephala e Chrysomya putoria (Diptera, Calliphoridae). Revta bras. Ent. 38 (1): 33-46.

RiCKLEFS, R.E. 1993. The economy of nature. New York, W.H. Freeman, 3rd edition, IX+576p.

RoBaCK, S.S. 1951. A classification of the muscoid calyptrate Diptera. Ann. Entomol. Soc. Amer. 44: 327-361.

Silveira Neto, S.; O. NaKano; D. Barbin \& N.A. Villa Nova. 1976. Manual de ecologia dos insetos. São Paulo, Editora Agronômica Ceres Ltda., 419p.

SMith, P.H.; L. Barton-Browne \& A.C.M. van Gerwen. 1989. Causes and correlates of loss and recovery of sexual receptivity in Lucilia cuprina females after their first mating. J. Insect Behavior 2 (3): 325-337.

SouTHwood, T.R.E. 1978. Ecological methods. With particular reference to the study of insect populations. London, Chapman and Hall, 2nd ed., XXIV+524p.

VIEIRA, S. 1981. Introdução à bioestatística. Rio de Janeiro, Editora Campus, $2^{\mathrm{a}}$ edição, 203p.

VIEIRA, S. \& R. HoffmanN. 1989. Estatística experimental. São Paulo, Editora Atlas S.A., 179p.

ZDAREK, J. \& G. FRAENKEL. 1972. The Mechanism of Puparium Formation in Flies. J. Exp. Zool. 179: 315-324.

ZUMPT, F. 1965. Myiasis in man and animals in the Old World. London, Butterworths, 267p.

Recebido em 08.V.1996; aceito em 05.X.1996. 